\title{
Article \\ Application of Barley Tweaky Spike Mutants for the Study of Effects of Plant Immunity-Related Substances
}

\author{
Raimondas Šiukšta ${ }^{1, *(\mathbb{D}, \text { Virginija Vaitkūnienè }}{ }^{1,2}$, Rimutè Mačkinaite $^{3}$ and Vytautas Rančelis ${ }^{1}$ \\ 1 Institute of Biosciences, Life Sciences Centre, Vilnius University, Saulètekio Ave. 7, \\ LT-10257 Vilnius, Lithuania; virginija.vaitkuniene@gf.vu.lt (V.V.); vytautas.rancelis@gf.vu.lt (V.R.) \\ 2 Botanical Garden of Vilnius University, Vilnius University, Kairènai Str. 43, LT-10239 Vilnius, Lithuania \\ 3 Nature Research Centre, Institute of Botany, Žaliujuc ežeru Str. 49, LT-12200 Vilnius, Lithuania; \\ rimute.mackinaite@botanika.lt \\ * Correspondence: Raimondas.Siuksta@gf.vu.lt
}

Citation: Šiukšta, R.; Vaitkūnienè, V.; Mačkinaitè, R.; Rančelis, V.

Application of Barley Tweaky Spike Mutants for the Study of Effects of Plant Immunity-Related Substances. Agronomy 2021, 11, 2180. https:// doi.org/10.3390/agronomy11112180

\begin{abstract}
Barley developmental mutants tweaky spike ( $t w)$ with disturbed auxin pathways possess a unique feature of an increased level of mouldy germinating grains (MGG), which serves as a convenient model to investigate the effects of plant immunity-related substances. The effects of the auxin 2,4-dichlorophenoxyacetic acid (2,4-D), auxin inhibitors, salicylic acid (SA), and transcinnamic acid (TCA) were studied using the $t w$-WT system in surface-sterilized and unsterilized germinating grains under high rates of natural infection. Significant differences among the allelic tw mutants were revealed at the natural MGG level and in response to 2,4-D, SA, and TCA. The most effective means against MGG were sterilization and TCA. 2,4-D inhibited root growth in $t w$ and $t w_{2}$ mutants, occurring only in unsterilized and not sterilized germinating grains, while the opposite was observed for TCA and SA. The tw mutations influenced variations in the seed-borne fungal spectra, decreasing the frequency of Bipolaris sorokiniana and increasing Fusarium spp. Hypochlorite-based surface sterilization methods should be used with caution in studies where the action of exogenous 2,4-D will be analysed in germinating grains. Auxin pathway disturbances specific for pleiotropic tw mutants are generally restricted to organogenesis but not to germination events.
\end{abstract}

Keywords: barley; MGG assay; salicylic acid; trans-cinnamic acid; tweaky mutants; 2,4-D

Academic Editors: Chiara Pastore and Antonio Cellini

Received: 20 September 2021

Accepted: 26 October 2021

Published: 28 October 2021

Publisher's Note: MDPI stays neutral with regard to jurisdictional claims in published maps and institutional affiliations.

\section{Introduction}

Grain contamination with fungi and their produced mycotoxins is not only a problem for organic producers but also for conventional agriculture [1]. For barley, special attention is required for malt and beer contamination with mycotoxins and their proper control and avoidance [2].

A group of barley pleiotropic tweaky spike ( $t w)$-type mutants $\left(t w, t w_{1}, t w_{2}\right)$ possess a specific tweaked spike structure (Figure S1) and an irregular transformation of lodicules, which are grass-specific floral organs, intoreproductive or chimeric organs. They are also characterized by higher susceptibility to Claviceps purpurea and Ustilago nuda, and increased levels of germinating grain moulding [3,4]. The higher susceptibility of tw-type mutants to fungal pathogens may be explained by their polar spike architecture with the semisterile lower part of a spike and overdeveloped multi-rowed upper part, in which flowers with ectopically developed extra floral organs become partially opened during the grain development stage, making it more accessible to external fungal spores and rainwater [3]. Nevertheless, the increased level of mouldy germinating grains (MGG) is unique and deserves further study. Grain infection by fungal pathogens is among the main sources of plant infection [5,6], and grain-borne fungi cause significant grain yield and quality losses via toxin production due to the resulting decrease in the germination rate and the increased number of abnormal and affected seedlings [7]. Although the mechanisms leading to MGG of barley tw-type mutants are poorly studied, this phenomenon can still be employed as 
a convenient and simple model to test the effects of plant immunity-related substances, making barley tw-type mutants a suitable genetic system for an MGG-based assay.

Our recent studies have related the tw phenotype to disrupted auxin physiology $[8,9]$, providing a pretext to study the role of auxin in the MGG phenomenon. Depending on lifestyle, phytopathogens develop means for controlling plant growth by modulating endogenous auxin synthesis and signalling [10]. Moreover, endophytic auxin-producing fungi may improve plant growth, suppress seed-borne infections, and enhance resistance to abiotic stresses [11,12]. On the other hand, plants evolve mechanisms to repress auxin signalling during pathogen infection as a defence strategy $[13,14]$. The downregulation of auxin signalling is part of the pathogen-induced host immune response [15]. Mutations in genes responsible for auxin synthesis and signalling are most often used to study the role of auxin in response to pathogen infection. Through the use of these mutations, significant differences in plant auxin-pathogen relationships have been demonstrated for the infection stage [16], different species of the same fungal genus or the same fungus on different plants [17].

The present study aimed to relate the increased levels of MGG in tw mutants with disturbances in the auxin pathway and to employ MGG as an assay to test the effects of potential modifying factors against pathogen manifestation in germinating grains. The effects of grain sterilization and various treatments, including synthetic auxin 2,4-dichlorophenoxyacetic acid (2,4-D), auxin transport inhibitor 9-hydroxyfluorene-9-carboxylic acid (HFCA), antiauxin p-chlorophenoxyisobutyric acid (PCIB), phytohormone salicylic acid (SA), and its precursor trans-cinnamic acid (TCA), were studied on MGG and root growth inhibition, the most pronounced indicator of response to 2,4-D [18], using three allelic tw-type mutants $\left(t w, t w_{1}, t w_{2}\right)$. In previous studies, the tw-type mutants were used to study the effects of the antioxidants ascorbic acid and glutathione [19] and SA [20] on MGG frequency and root growth, and the transgenerational transmission of the effects of SA treatment [21]. In the present study, the effects of exogenous 2,4-D, auxin inhibitors, SA, and TCA on MGG and root growth, were compared using a palette of various tweaky-type mutants and WT. The influence of tw-type mutations on the frequency of Bipolaris and Fusarium, two predominant genera of fungi found in the internal tissues of all tested barley genotypes, is also emphasized.

\section{Materials and Methods}

\subsection{Plant Material and Growth Conditions}

The plant material used for the study was propagated in an experimental field at the Botanical Garden of Vilnius University, using $2 \times 2 \mathrm{~m}^{2}$ plots per genotype, $600-800$ plants per plot. All the plant material had been cultivated for many years without pesticide exposure to retain the natural diversity and frequency of plant pathogens.

Recessive allelic tweaky spike-type mutants, $t w, t w_{1}$ and $t w_{2}$, were induced by chemical mutagenesis using ethylene imine in the barley cv. Auksiniai II, which has the same genetic background, was used as the Wild type (WT) (Figure S1). During the early phase of stabilization $\left(\mathrm{F}_{4}-\mathrm{F}_{6}\right), t w_{1}$ and $t w_{2}$ mutants underwent a period of genetic instability, which led to complete or incomplete reversions to the WT phenotype $(t w \rightarrow T w)$, resulting in a large collection of revertants. In the case of incomplete reversion, some revertants preserved several $t w$-specific features, such as higher protein content in grains and increased resistance to lodging [22]. In the present study, six revertants (N1, N13 and C1-from tw 1 , N46, C6 and C7-from $t w_{2}$ ) were used for the additional comparison of internal grain fungi.

Two other tweaky-type mutants, tweaky N18 (twN18) and tweaky and missing kernels (twmk), were also included in the analysis of 2,4-D effects on MGG and root growth. Both mutants were obtained from the USDA-ARS National Small Grains Collection (Aberdeen, ID, USA) and possess tweaked spikes, but their susceptibility to fungal infections is unknown. The complementation test revealed twN18 and twmk mutants to belong to complementation groups other than the allelic tw-type mutants [23]. The grains used in the present study for the MGG analysis were selected from different years of growth, and 
stored at $+4{ }^{\circ} \mathrm{C}$ in the dark until the analysis was performed. The years of reproduction are indicated in the legends of Figures 3-5 and the footers of Tables S3-S5.

\subsection{Mouldy Germinating Grain (MGG) Test}

All manipulations were performed under sterile conditions. The seed material was divided into two groups: (1) nonsterilized, deionized water-imbibed grains to evaluate the natural infection level and (2) grains surface-sterilized with a water-diluted commercial bleach ACE solution $(1: 1, v / v)$ for $15 \mathrm{~min}$ and then washed with sterile water three times for $2 \mathrm{~min}$. The grains were then soaked in solutions of synthetic auxin 2,4-D (50-800 mg L-1), the auxin transport inhibitor 9-hydroxyfluorene-9-carboxylic acid (HFCA) or antiauxin p-chlorophenoxyisobutyric acid (PCIB) $(200 \mu \mathrm{M})$, phytohormone SA or its precursor TCA (0.25-1.0 mM) for $12 \mathrm{~h}$, rewashed with autoclaved water and placed in Petri dishes (ten grains per dish) with three layers of wet filter paper. The frequencies of MGG, germination rate, and root length were determined after five days of growing at $25{ }^{\circ} \mathrm{C}$ in the dark. Mouldy grains were scored and removed from the Petri dishes every day to prevent infection of the neighbouring grains. All the experiments were performed in three independent replicates, ten Petri dishes with 10 grains per dish (i.e., 100 grains in total) were used per treatment. For root length measurements, roots of 30 germinating grains were measured in total (i.e., 10 germinating grains per experimental replicate). The concentrations of the compounds were selected from small-scale experiments and our previous studies [8,9]. 2,4-D was manufactured by Alfa Aesar (Germany), and all the other compounds were obtained from Sigma-Aldrich (USA).

\subsection{Identification of Internal Fungi in Barley Grains}

The pure culture method was applied for the detection of fungi inside the seeds [24]. The grains were sterilized with $3 \% \mathrm{NaClO}$ for $2 \mathrm{~min}$ and washed with sterile water three times for $2 \mathrm{~min}$. The grains were then dried with sterile filter paper, placed on Petri dishes containing malt extract agar (MEA) medium (2\%) and streptomycin $\left(250 \mathrm{mg} \mathrm{L}^{-1}\right)$, and maintained at $24{ }^{\circ} \mathrm{C}$ for seven days in the dark. The fungi were identified according to their morphological and cultural characteristics as described by Mačkinaite [25].

\subsection{Investigation of Effects of Meal on B. sorokiniana Growth}

To study the potential inhibitory effects of meal from $W T$ or allelic mutants $t w, t w_{1}$, and $t w_{2}$ under the background of SA or TCA, pure cultures of B. sorokiniana were isolated from sterilized barley grains using a single spore technique and deposited in the collection of the Institute of Botany, Nature Research Centre, Vilnius, Lithuania. The isolate of $B$. sorokiniana was reidentified by a taxon-specific polymerase chain reaction. Briefly, genomic DNA was extracted from $50 \mathrm{mg}$ of wet mycelium using Fungi/Yeast Genomic DNA Isolation Kit (Norgen Biotek Corporation, Thorold, Canada) following the manufacturer's recommendations. Species-specific PCR was carried out according to [26] using the Green PCR Master Mix (Thermo Scientific ${ }^{\mathrm{TM}}$, USA) and species-specific primer pair (FW 5'GGTCCGAGACAACCAACAA3' and RV 5'AAAGAAAGCGGTCGACGTAA3'). The 600 bp species-specific SCAR PCR product was electrophoresed in $1.2 \%$ agarose gel containing ethidium bromide $\left(0.5 \mu \mathrm{g} \mathrm{mL}^{-1}\right)$ in $1 \times$ Tris-Borate-EDTA buffer.

Meals from $W T$ and different $t w$-type mutants $\left(60 \mathrm{~g} \mathrm{~L}^{-1}\right)$ and SA or TCA $(0-1 \mathrm{mM})$ were added directly to the MEA medium before autoclaving. The diameter of $B$. sorokiniana colonies was measured after seven days of incubation at $24{ }^{\circ} \mathrm{C}$ in the dark.

\subsection{Statistical Analysis}

The results are representative of three independent experiments performed at least in triplicate and are shown as the mean values \pm standard error (SE) of the mean in the tables and figures. The assumption of data normality was assessed through the ShapiroWilk test using Past (version 3.26) software. Since at least some of the data sets did not follow a normal distribution, a nonparametric Kruskal-Wallis rank-sum (omnibus) test was 
performed using Statistica 64 (version 12.0) software. Dunn's test with Benjamini-Hochberg (FDR) adjustment was used as a post hoc test to examine the differences between the sterilized and unsterilized grains or multiple pairwise comparisons of different treatments and the control.

\section{Results}

3.1. The Action of 2,4-D, SA and TCA on MGG and Root Growth of Allelic Tweaky Spike Mutants

Naturally, grain sterilization before germination is an effective treatment against MGG. In most cases studied, the MGG level was significantly lower in surface-sterilized grains than in unsterilized grains under the same experimental conditions, and independent of the plant genotype and the studied 2,4-D concentrations (Figures 1a and 2a, Tables S1a and S2a).
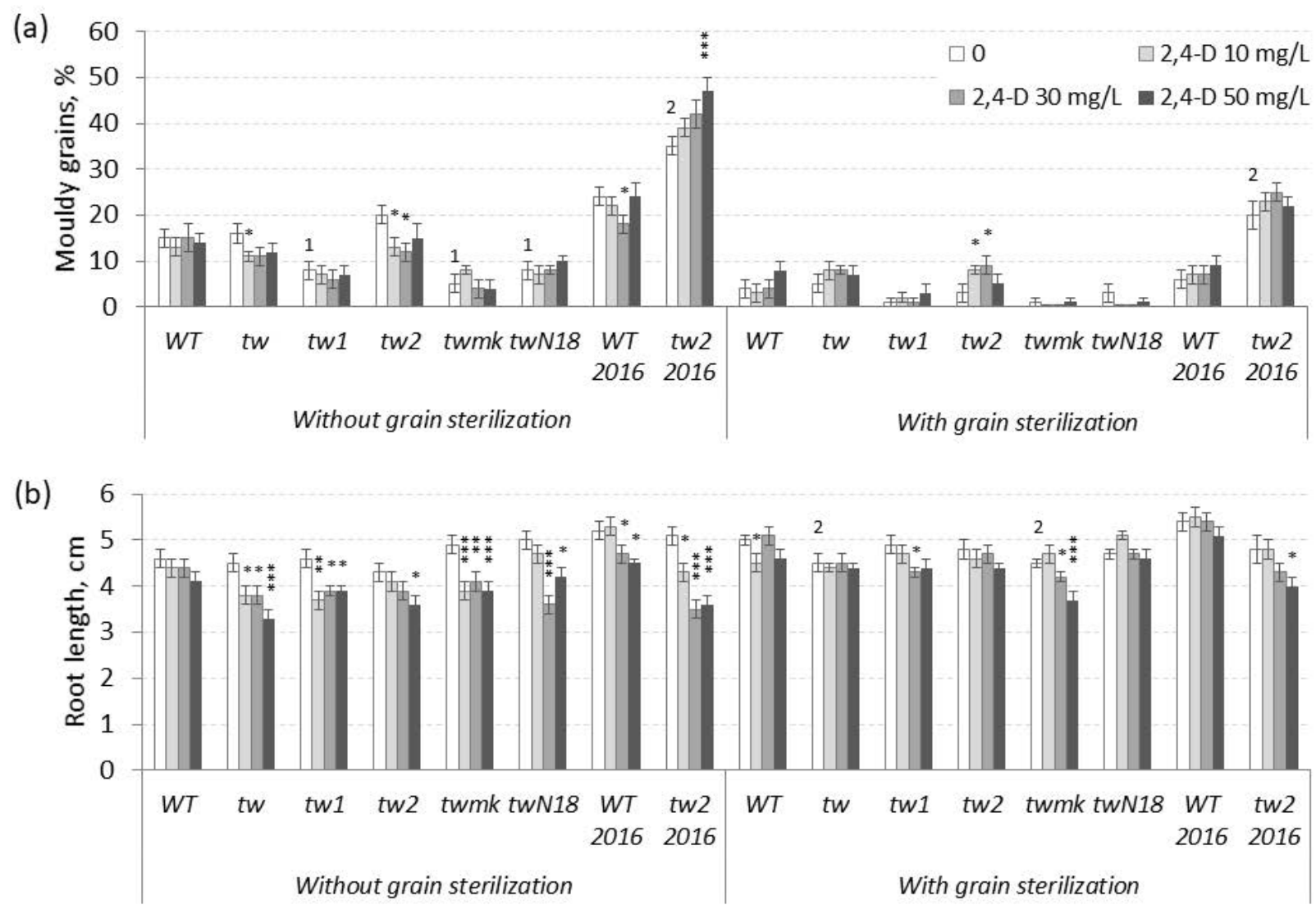

Figure 1. Effects of 2,4-D over a $10-50 \mathrm{mg} \mathrm{L}^{-1}$ range on barley tweaky-type mutants. (a) The frequency of mouldy grains (\%) and $(\mathbf{b})$ the root lengths $(\mathrm{cm})$ of unsterilized and sterilized germinating grains measured after 5 days. For mouldy grains, $\mathrm{n}=10$ Petri dishes (100 grains); for root length $\mathrm{n}=30$; for $t w_{2}, \mathrm{n}=15$ Petri dishes (150 grains) and $\mathrm{n}=60$. WT2016 and $t w_{2} 2016$, grain reproduction in 2016; other material, grain reproduction in 2013; the MGG assay was performed in 2017. The asterisks represent significant differences $\left({ }^{*} p<0.05 ;{ }^{* *} p<0.01 ;{ }^{* *} p<0.001\right)$ between the control and the 2,4-D treatment. The numbers denote significant differences $\left({ }^{1} p<0.05 ;{ }^{2} p<0.01\right)$ between the controls of the tw-type mutant and the WT. 


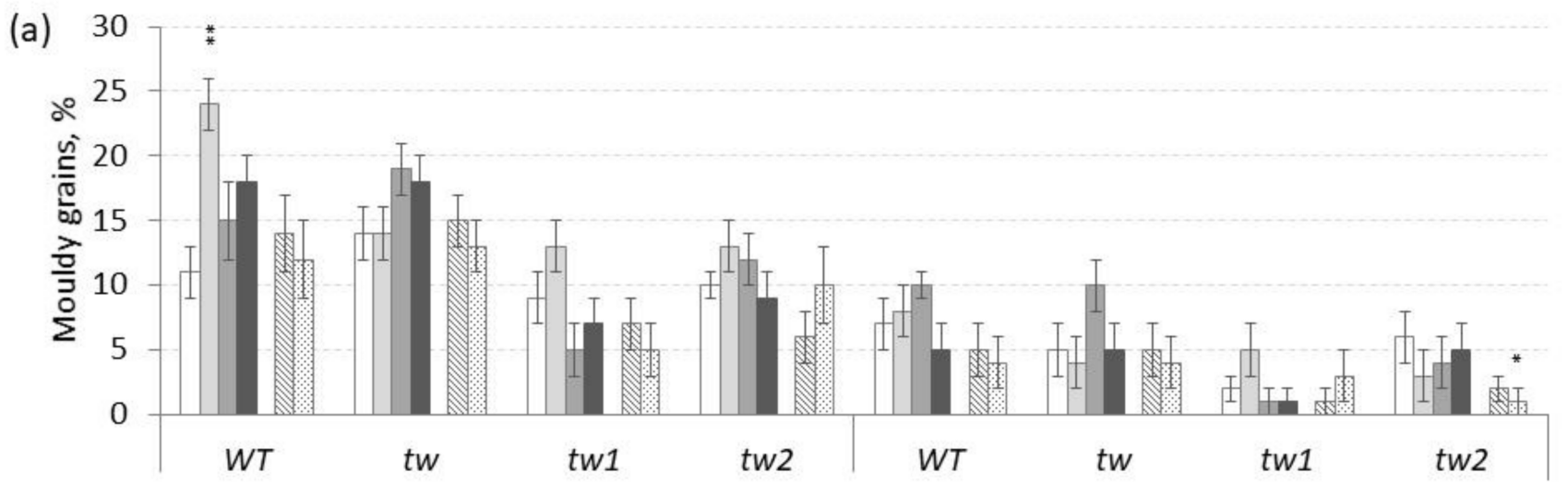

Without grain sterilization

With grain sterilization

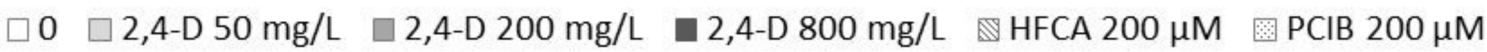
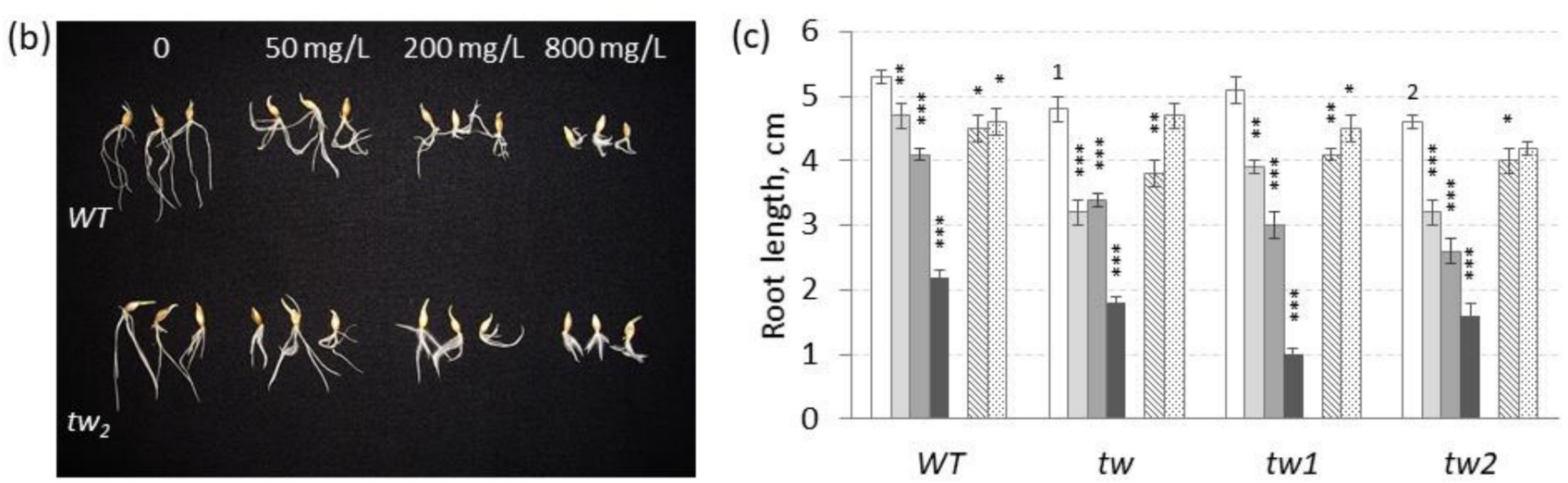

Figure 2. Effects of 2,4-D over a range of $50-800 \mathrm{mg} \mathrm{L}^{-1}$ and the auxin inhibitors HFCA and PCIB on (a) the frequency of mouldy grains $(\%)$ and $(\mathbf{b}, \mathbf{c})$ the root length $(\mathrm{cm})$ of unsterilized germinating grains of $w$ mutants and the WT, as measured after 5 days. For mouldy grains, $\mathrm{n}=10$ Petri dishes (100 grains); for root length, $\mathrm{n}=30$. Grain was produced in 2013 , and the MGG assay was performed in 2017. The asterisks represent significant differences $\left({ }^{*} p<0.05 ;{ }^{* *} p<0.01 ;{ }^{* * *} p<0.001\right)$ between the control and the 2,4-D treatment. The numbers denote significant differences $\left({ }^{1} p<0.05 ;{ }^{2} p<0.01\right)$ between the controls of the tw-type mutant and the WT.

In the range of $10-50 \mathrm{mg} \mathrm{L}^{-1}$, an appreciable inhibitory effect of 2,4-D on the root growth of allelic tw-type mutants depended on (1) the plant genotype and (2) the sterilization status of grains (Figure $1 \mathrm{~b}$ and Table S1b). In most cases, 2,4-D significantly inhibited root growth only in unsterilized germinating grains of all tested genotypes, including the nonallelic twN18 and twmk mutants. The twmk mutant was the most sensitive to 2,4-D among all tested tweaky-type mutants. In contrast, 2,4-D-induced root growth inhibition in sterilized germinating grains mostly in a nonsignificant manner (Figure $1 \mathrm{~b}$ and Table $\mathrm{S} 1 \mathrm{~b}$ ).

The tested lower 2,4-D concentrations $\left(10-50 \mathrm{mg} \mathrm{L}^{-1}\right)$ revealed an interesting dependence of 2,4-D-induced root growth inhibition on grain sterilization status; consequently, the effect of elevated 2,4-D concentrations was investigated in further experiments. In the range of 50-800 $\mathrm{mg} \mathrm{L}^{-1} 2,4-\mathrm{D}$, a significant effect of 2,4-D on MGG was observed only in unsterilized grains of WT ( $p=0.0026)$, in which 2,4-D increased the level of MGG (Figure 2a and Table S2a), while in the range of $10-50 \mathrm{mg} \mathrm{L}^{-1} 2,4-\mathrm{D}$, a significant increase in MGG was observed only in sterilized grains of the $t w_{2}$ genotype ( $p=0.024$; Figure 1a and Table S1a).

In contrast to the effect of the lower concentrations, the higher concentrations (50-800 mg L $\mathrm{L}^{-1}$ ) of 2,4-D induced a significant decrease in root length independent of the plant genotype and the grain sterilization conditions, and the inhibitory effect of 2,4-D 
on root growth was dose-dependent (Figure 2b,c and Table S2b). The root growth of the $t w$ and $t w_{2}$ allelic mutants, but not the $t w_{1}$ allelic mutant, was weaker than that of WT germinating grains. An unsterilized grain background better revealed the inhibitory effect of 2,4-D on the germination rate, which was uniform independent of the plant genotype. In turn, grain sterilization revealed better differences among allelic mutants in the response to 2,4-D according to the germination rate (Table S2c). In general, 2,4-D in the range of $50-800 \mathrm{mg} \mathrm{L}^{-1}$ inhibited root length independent of the plant genotype (Figure 2c), while in the range of $10-50 \mathrm{mg} \mathrm{L}^{-1} 2,4-\mathrm{D}$, differences between $W T$ and tw-type mutants and among allelic tw mutants themselves were observed (Figure 1).

Despite the proposed opposite effects to the action of 2,4-D, the auxin inhibitors HFCA and PCIB did not show a significant effect on MGG, except PCIB in sterilized grains of the $t w_{2}$ mutant, in which the MGG level decreased (Figure 2a and Table S2a). However, both auxin inhibitors suppressed root growth similarly to 2,4-D (Figure 2c and Table S2b).

Theoretically, the effects of TCA and SA are supposed to be opposite to those of 2,4-D, and TCA decreased the frequency of MGG in unsterilized germinating grains of the WT and all allelic tw-type mutants (Figure 3 and Table S3).

(a)

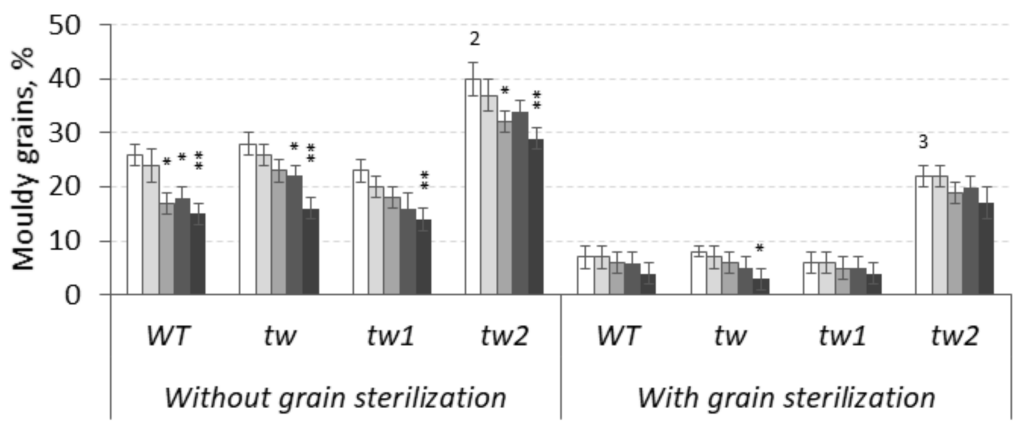

(b)

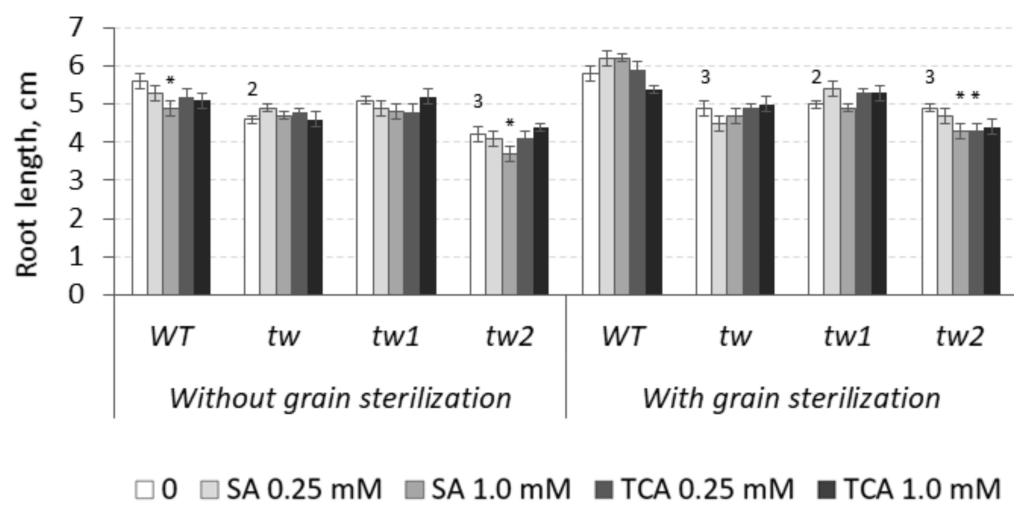

Figure 3. Effects of salicylic (SA) and trans-cinnamic (TCA) acids on (a) the frequency of mouldy grains $(\%)$ and $(\mathbf{b})$ the root lengths $(\mathrm{cm})$ of unsterilized and sterilized germinating grains of barley $t w$ mutants and the $W T$, as measured after 5 days. For mouldy grains, $\mathrm{n}=10$ (100 grains); for root length, $\mathrm{n}=30$. Grain was produced in 2016, and the MGG test was performed in 2020. The asterisks represent significant differences $\left({ }^{*} p<0.05 ;{ }^{* *} p<0.01\right)$ between the control and the SA or TCA treatment. The numbers denote significant differences $\left({ }^{2} p<0.01 ;{ }^{3} p<0.001\right)$ between the controls of the $t w$-type mutant and the WT.

However, in sterilized germinating grains, TCA decreased MGG at a significant level only in the allelic tw mutant, while SA decreased MGG at a significant level only in unsterilized grains of the $t w_{2}$ mutant (Figure 3 and Table S3a). Similar to 2,4-D, SA and TCA also inhibited root growth, but only in the allelic mutant $t w_{2}$ (Figure $3 \mathrm{~b}$ and Table S3b). Neither compound showed any effect on the grain germination rate (Table S3c). 


\subsection{Fungi Spectrum in the Internal Grain Tissues of Barley tw-Type Mutants and Revertants}

To reveal the possible differences in the fungal diversity in surface-sterilized mouldy germinating grains of tested barley genotypes, the spectrum of fungi species was investigated. Among the fungi that frequently reside in the internal tissues of barley grains, B. sorokiniana prevailed in all the tested plant genotypes (Figure 4 and Table S4). In addition to the $W T, t w_{1}$ and $t w_{2}$ mutants, the fungi spectra were also studied in several revertants that arose during the phase of stabilization of $t w_{1}$ and $t w_{2}$ mutants. The revertant studies allowed for a broader understanding of the differences between tw-type mutants and the WT.
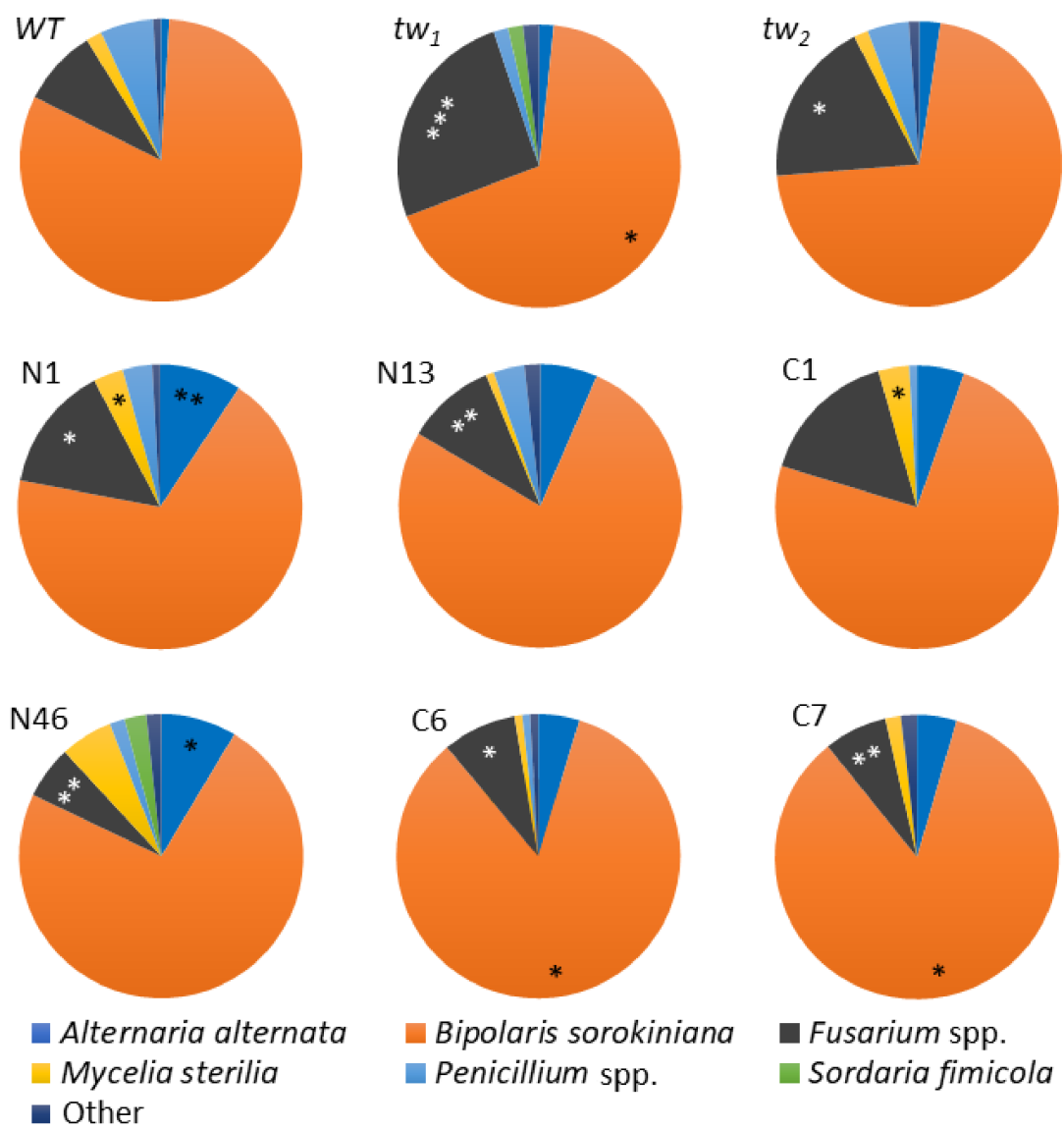

Figure 4. Spectra of fungi (\%) in the internal grain tissues of barley tw mutants and the WT. The middle row-revertants from $t w_{1}$; the lower row-revertants from $t w_{2}$. N-revertants with normal spike and floral structure, C-revertants with normal floral structure but compactoid spikes. Grain was produced in 2013, and the analysis was performed in 2014. The asterisks represent significant differences $\left({ }^{*} p<0.05 ;{ }^{* *} p<0.01 ;{ }^{* *} p<0.001\right.$ ) between the tw-type mutant and the WT (in the upper row) or between the revertant and the respective initial tw mutant (N1, N13 and C1 derived from $t w_{1}$, $\mathrm{N} 46, \mathrm{C} 6$ and $\mathrm{C} 7$-from $t w_{2}$ ).

In the grains of the $t w_{1}$ and $t w_{2}$ mutants, the B. sorokiniana frequency was lower than that in the WT strain, but the difference was only statistically significant in $t w w_{1}$. Interestingly, the level of B. sorokiniana was only significantly lower in grains of revertant N1 compared to $W T(p<0.05)$ and remained the same as in grains of its parental mutant $t w_{1}$. Such a tendency was not observed. A similar tendency was also observed in other revertants, except for the compactoid (C)-type revertants from $t w_{2}$, but only in an insignificant manner. However, a decrease in the Bipolaris proportion occurred at the expense of the increasing Fusarium portion in the fungi spectra, and the observed effect was statistically significant (Figure 4). Comparable results were also obtained after analysing the fungi spectra in 
the internal grain tissues in our previous studies [22]. This finding provided a pretext for studying the effects of grain meals made from the different $t w$-type allelic mutants and the WT on B. sorokiniana growth.

\subsection{The Impact of Meals from Grains of tw-Type Mutants on the Colony Growth of Bipolaris sorokiniana}

The growth of B. sorokiniana colonies on MEA media supplemented with meals prepared from the grounded dry grains of allelic mutants $t w, t w_{1}$, and $t w_{2}$ was compared with $B$. sorokiniana growth on MEA medium containing meals from the grains of WT. Additionally, the effects of the SA and TCA concentrations were investigated on such media (Figure 5). The meals from the allelic tw mutants significantly decreased the growth of B. sorokiniana colonies. In most cases, a further statistically significant decrease in Bipolaris colony growth occurred only after TCA but not SA addition. SA decreased the growth of $B$. sorokiniana in a concentration-dependent manner only in $t w_{2}$. TCA also showed a strong inhibitory effect on $B$. sorokiniana growth on MEA media with meals from the WT. Even the lowest concentration of TCA, $0.05 \mathrm{mM}$, significantly decreased the growth of Bipolaris colonies, and a further increase in TCA concentration did not enhance its inhibitory effect on B. sorokiniana growth in WT media (Figure 5).

(a)

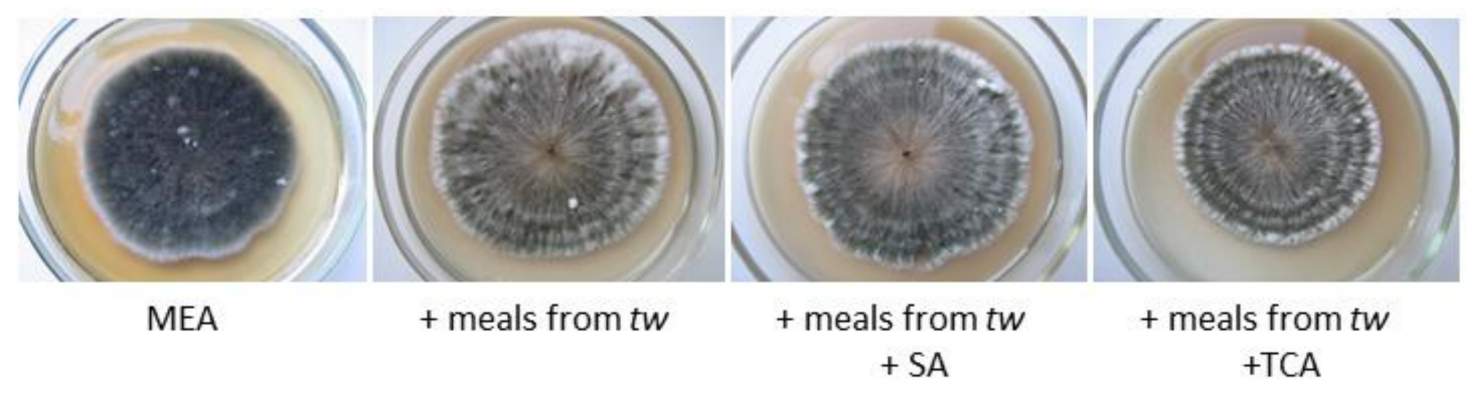

(b)

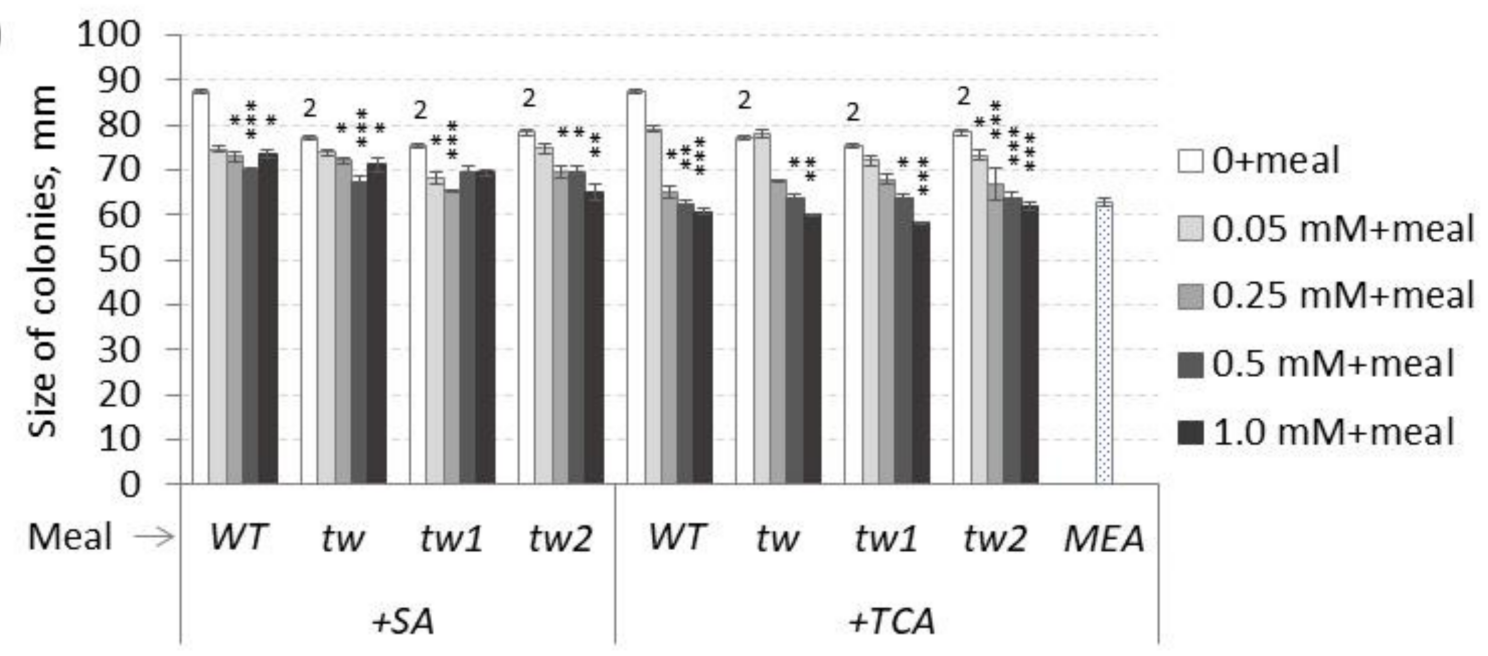

Figure 5. Effects of salicylic acid (SA) and trans-cinnamic acid (TCA) on the growth of Bipolaris sorokiniana after 7 days of growth on medium containing meal from $t w$. (a) The morphology of B. sorokiniana colonies grown on MEA media with different supplements. (b) Size of the colonies 7 days after inoculation. MEA, malt extract medium. Grain was produced in 2013, and the experiment was performed in 2014. The asterisks represent significant differences ${ }^{*} p<0.05 ;{ }^{* *} p<0.01$; $\left.{ }^{* * *} p<0.001\right)$ between the control and the SA or TCA treatment. The numbers denote significant differences $\left({ }^{2} p<0.01\right)$ between the controls of the tw-type mutant and the WT.

\section{Discussion}

Multi-year studies of tw-type mutants have revealed the significant variation in MGG expression observed in the seed material from different years and statistically significant 
differences in MGG levels between the allelic tw-type mutants (Table 1). Naturally, among the most important factors that influence the occurrence of fungal diseases is weather conditions during the growing season [27-29]. However, another source of such variations may lie in the highly variable expressivity of the tw phenotype. One of the main characteristics of $t w$-type mutants is the irregular transformations of lodicules, grass-specific floral organs, to sterile reproductive organs, which partially open the flowers and physically facilitate the penetration of pathogen spores and water into the developing grain [3]. Depending on the years, the fraction of aberrant flowers of mutants $t w, t w_{1}$, and $t w_{2}$ fluctuates in the ranges of $63-80 \%, 29-48 \%$ and $32-90 \%$ (respectively) [unpublished data], and such expressivity variations in flower structure from year to year can directly influence the quality of grains from different years.

Table 1. Variation in MGG frequencies (\%) in barley tweaky spike (tw) allelic mutants in different years of seed material growth.

\begin{tabular}{|c|c|c|c|c|c|c|}
\hline Year & Position in Spike & $W T$ & $t w$ & $t w_{1}$ & $t w_{2}$ & References \\
\hline 1992 & Total u.s. & $25 \pm 4$ & $42 \pm 2^{3}$ & $40 \pm 5^{1}$ & $38 \pm 5^{1}$ & \multirow{2}{*}[4]{} \\
\hline 1993 & Total u.s. & $19 \pm 4$ & $33 \pm 2^{2 c}$ & $21 \pm 4^{c}$ & $45 \pm 5^{3 c}$ & \\
\hline 1996 & Total u.s. & $11.0 \pm 2.2$ & - & $34.5 \pm 3.4^{3}$ & $28.5 \pm 3.2^{3}$ & [19] \\
\hline 2002 & Total u.s. & $11.6 \pm 2.3$ & $18.0 \pm 2.7$ & $18.4 \pm 2.8$ & $19.2 \pm 2.8^{1}$ & [21] \\
\hline 1999 & Total u.s. & $7.8 \pm 1.0$ & $18.7 \pm 1.6^{3}$ & $20.2 \pm 2.9^{2}$ & $17.0 \pm 1.5^{3}$ & [30] \\
\hline 2012 & Total u.s. & $34.5 \pm 2.9$ & - & $32.0 \pm 2.6^{c}$ & $48.0 \pm 2.5^{3 c}$ & Unpublished data \\
\hline 2013 & Total u.s. & $11 \pm 2$ & $14 \pm 2$ & $9 \pm 2$ & $10 \pm 1$ & Present study \\
\hline 2013 & Total st. & $7 \pm 2$ & $5 \pm 2$ & $2 \pm 1$ & $6 \pm 2$ & [30] \\
\hline 2013 & Total u.s. & $15 \pm 2$ & $16 \pm 2$ & $8 \pm 2^{1 a}$ & $20 \pm 2^{b}$ & Unpublished data \\
\hline 2013 & Total st. & $4 \pm 2$ & $5 \pm 2$ & $1 \pm 1$ & $3 \pm 2$ & \multirow{5}{*}{ Present study } \\
\hline 2016 & Total u.s. & $24 \pm 4$ & - & - & $35 \pm 2^{2}$ & \\
\hline 2016 & Total st. & $6 \pm 2$ & - & - & $20 \pm 3^{2}$ & \\
\hline 2017 & Total u.s. & $6 \pm 2$ & $13 \pm 2^{1 a}$ & - & $19 \pm 2^{3 a}$ & \\
\hline 2018 & Total u.s. & $8 \pm 2$ & - & $17 \pm 2^{2}$ & $22 \pm 2^{3}$ & \\
\hline
\end{tabular}

The present study revealed a smaller than expected effect of the exogenous synthetic auxin 2,4-D and both auxin inhibitors HFCA and PCIB on MGG frequency in tw-type mutants, considering their dramatic rescue effects on variations in spike and floral structure (respectively), which were revealed in our previous works $[8,9]$. Such a negligible effect of 2,4-D and both auxin inhibitors on MGG frequency of different tweaky-type mutants, strongly suggests that auxin pathway disturbances in $t w$-type mutants are generally restricted to the spike and floral structure but not to germination events.

A notable feature of the grain material used in the present study is the pesticide-free production mode, which was applied for many years. Under the background of high natural infection, the most effective means against the moulding of germinating grains is widely used grain surface sterilization [31-33], which was effective independently of the plant genotype and seed material from different years. However, a comparison of sterilized and unsterilized seed material appeared to be an effective strategy for the auxinpathogen relationship study. A significant increase in the MGG level was only determined after 2,4-D treatment of unsterilized WT grains (Figure 1a, Table S1a), while the inhibitory effects of salicylic acid and especially trans-cinnamic acid on the MGG frequency were also statistically significant only for unsterilized germinating grains of the tested plant genotypes (Figure 3a). Comparison of sterilized and unsterilized grains in the MGG assay 
also revealed differences among the allelic mutants $t w$, $t w_{1}$, and $t w_{2}$ in response to 2,4-D. Allelic differences in the pathogen response related to auxin action are poorly studied. Stotz et al. [34] determined differences among allelic mutants in the transcriptional repressor auxin response factor 2 (arf2) gene in response to the ascomycete Sclerotinia sclerotiorum. From the multi-year studies of $t w$-type mutants, it was concluded that $t w_{2}$ is the most sensitive to MGG (Table 1). Comparison of sterilized and unsterilized grains in the present analysis also confirmed $t w_{2}$ to be the most responsive to 2,4-D in the MGG assay (Figures 1 and 2).

The increase in MGG frequency after 2,4-D treatment in some cases of the present study (Figures 1a and 2a) coincides with the known auxin effects on phytopathogens. Endogenous auxin was demonstrated to enhance the invasion of biotrophs and to inhibit the development of necrotrophs [13,35-37]. In contrast, exogenously applied auxin, in general, showed the opposite effect when the invasion of nectrotrophs was escalated after auxin application $[38,39]$. The predominant internal fungi in all tested barley genotypes belonged to the Bipolaris and Fusarium genera (Figure 4), both of which are considered hemibiotrophic, exhibiting a brief biotrophic phase before switching to the dominant necrotrophic phase $[40,41]$. This conclusion is also supported by the inhibitory effects of SA and TCA on MGG revealed in the present study. It was demonstrated that SA suppresses pathogen growth in plants through the repression of auxin signalling [42,43]; therefore, the SA and auxin pathways act in a mutually antagonistic manner during plant defence responses $[13,35,44,45]$. TCA, one of the precursors of SA, also has antifungal properties and is considered a natural protective substance against phytopathogens [46,47]. TCA was long considered an auxin transport inhibitor, but recent works have suggested that another isomer, cis-cinnamic acid, but not TCA, is a potent inhibitor of auxin efflux, hence the exact physiological activity of TCA has remained a matter of debate [48].

The effects of tweaky spike mutations on fungi spectra are also notable. In internal grain tissues of all tested barley genotypes, the prevailing fungus in the spectra was Bipolaris sorokiniana (teleomorph: Cochliobolus sativus) (Figure 4). This agrees with recent publications on fungal spectra in barley grains in the Baltic region $[49,50]$. B. sorokiniana causes severe diseases and significant yield losses mainly in warm humid growing regions; nevertheless, it has spread towards the Northern Hemisphere [6,51]. The present study shows that its spread strongly depends on the plant genotype. In both tw-type mutants and most revertants tested, a decrease in the B. sorokiniana proportion and an increase in the Fusarium spp. proportion occurred in the fungi spectra (Figure 4). This trend suggests that the grains of $t w$-type mutants contain substances that are unfavourable for $B$. sorokiniana growth. The following supposition was also confirmed by $B$. sorokiniana growing on media supplemented with meals from individual $t w$ allelic mutants and the WT. A decrease in $B$. sorokiniana in the fungal spectra of $t w$-type mutants coincides with the growth inhibition of $B$. sorokiniana colonies on media with the addition of meals from all allelic tw mutants (Figure 2).

The present study showed that more appreciable conclusions on the action of the modifying factors could be made when the MGG assay is performed in parallel with the root growth test. The inhibition of root elongation of germinating grains is one of the earliest and most distinct symptoms exhibited in response to auxins, especially 2,4-D [18], but auxin promotes lateral root formation [13], and this auxin feature is related to pathogen invasion [17]. In the present study, significant differences in 2,4-D-induced root growth inhibition among the different allelic tw-type mutants were revealed only in the lower range (10-50 $\mathrm{mg} \mathrm{L}^{-1}$ ) of 2,4-D concentrations (Figure $1 \mathrm{~b}$ ). Moreover, significant root length inhibition with 2,4-D in the allelic mutants $t w$ and $t w_{2}$ and the nonallelic mutant $t w N 18$ was only observed in unsterilized germinating grains, whereas in sterilized grains, root growth inhibition in these mutants was absent (Figure 1). While differences in MGG frequency between sterilized and unsterilized grains are naturally expected, the dependence of root growth after 2,4-D treatment on grain sterilization status was quite an unexpected phenomenon. Hypochlorite-based agents, including commercial bleach, are routinely used for surface sterilization of various plant materials [32,52]. Hypochlorite was 
proposed to react with the seed surface, forming a chlorine cover that is not completely removed by rinsing, and subsequently can be converted into highly toxic chloramines that easily penetrate plant tissues [32]. Furthermore, various salts are known to antagonize the phytotoxicity of several herbicides, including 2,4-D [53,54]. After surface sterilization with commercial bleach, nonremovable chlorine compounds can antagonise exogenously applied 2,4-D and subsequently diminish the effect of root growth inhibition in comparison to that of unsterilized 2,4-D-treated grains. This observation highlights the importance of comparing sterilized and unsterilized grain conditions in studies of plant-auxin-pathogen relationships where the action of exogenous auxin will be analysed in germinating grains since hypochlorite-based sterilization itself can lead to underestimation of the 2,4-D effect on root growth.

\section{Conclusions}

Our findings allow us to reach a number of conclusions. The effect of exogenous 2,4-D on barley MGG coincides with the role of auxin in the invasion of necrotrophs, but its effect on MGG was found to be lower, as may be expected based on the effects of 2,4-D on spike structure.

The effects of SA, TCA, and 2,4-D on MGG depended on the grain sterilization status.

The tweaky spike mutation caused variations in the fungi spectra in the germinating barley grains by decreasing the B. sorokiniana and increasing the Fusarium spp. proportions. This result agrees with the negative effects of meals from the $t w_{2}$ mutant on B. sorokiniana growth.

The effect of low doses of 2,4-D on barley root growth depended on the grain sterilization status, suggesting hypochlorite-based surface sterilization methods should be used with caution in studies where the action of exogenous 2,4-D will be analysed in germinating grains.

A group of $t w$-type barley mutants is a convenient model for the investigation of immunity-related substances in barley MGG.

Supplementary Materials: The following are available online at https://www.mdpi.com/article/10 .3390 /agronomy $11112180 / \mathrm{s} 1$, Table S1. Effects of 2,4-D over a $10-50 \mathrm{mg} \mathrm{L}^{-1}$ range on the frequency of mouldy germinating grains (a), root length (b) and grain germination rate (c) of barley tw mutants and the WT. (d) $p$ values of differences between sterilized and unsterilized grains under different experimental conditions. Table S2. Effects of 2,4-D over the $50-800 \mathrm{mg} \mathrm{L}^{-1}$ range and the auxin inhibitors HFCA and PCIB on the frequency of mouldy germinating barley grains (a) root length (b) and grain germination rate (c) of $t w$ mutants and the WT. (d) $p$ values of differences between sterilized and unsterilized grains under different experimental conditions. Table S3. Effects of salicylic acid (SA) and trans-cinnamic acid (TCA) on the frequencies of mouldy germinating grains (a) root length (b) and germination rate (c) of barley tw mutants and the WT. (d) $p$ values of differences between sterilized and unsterilized grains under different experimental conditions. Table S4. Frequency of fungi in the internal grain tissues of barley tw mutants, revertants and the WT. Figure S1. Spikes of barley genetic material used in the present study. From left: WT (cv. Auksiniai II), tweaky spike, tweaky N18, tweaky and missing kernel; and revertants: C, compactoid and N, normal spike shape.

Author Contributions: Conceptualization, R.Š. and V.R.; Investigation, R.Š., V.V. and R.M.; Methodology, R.Š., V.V. and R.M.; Supervision, V.R.; Visualization, R.Š.; Writing-original draft, R.Š. and V.R.; Writing-review \& editing, R.Š., V.V., R.M. and V.R. All authors have read and agreed to the published version of the manuscript.

Funding: This research received no external funding.

Institutional Review Board Statement: Not applicable.

Informed Consent Statement: Not applicable.

Data Availability Statement: The data presented in this study are available in the Supplementary Material of this article.

Conflicts of Interest: The authors declare no conflict of interest. 


\section{References}

1. Pinotti, L.; Ottoboni, M.; Giromini, C.; Dell'Orto, V.; Cheli, F. Mycotoxin contamination in the EU feed supply chain: A focus on cereal byproducts. Toxins 2016, 8, 45. [CrossRef] [PubMed]

2. Pascari, X.; Ramos, A.J.; Marín, S.; Sanchís, V. Mycotoxins and beer. Impact of beer production process on mycotoxin contamination. A review. Food Res. Int. 2018, 103, 121-129. [CrossRef] [PubMed]

3. Rančelis, V.; Žilinskaitè, S.; Vaitkūnienè, V.; Kačergius, A.; Kasparavičius, J. Immunodeficiency of barley allelic mutants 'tweaky spike'.1. Susceptibility to Ustilago nuda (Jens.) Rostr. and Claviceps purpurea Tul. Biologija 1994, 4, 14-22.

4. Mačkinaitè, R.; Kačergius, A.; Kasparavičius, J.; Balčiūnienė, L.; Vaitkūnienė, V.; Žilinskaitè, S.; Rančelis, V. Immunodeficiency of barley allelic mutants 'tweaky spike'. II. Mildewed germinating grains and micromycetes. Biologija 1996, 4, 11-18.

5. Assunção, R.; Silva, M.J.; Alvito, P. Challenges in risk assessment of multiple mycotoxins in food. World Mycotoxin J. 2016, 9 , 791-811. [CrossRef]

6. Bengyella, L.; Iftikhar, S.; Nawaz, K.; Fonmboh, D.J.; Yekwa, E.L.; Jones, R.C.; Njanu, Y.M.T.; Roy, P. Biotechnological application of endophytic filamentous Bipolaris and Curvularia: A review on bioeconomy impact. World J. Microbiol. Biotechnol. 2019, 35, 69. [CrossRef] [PubMed]

7. Janssen, E.M.; Liu, C.; Van der Fels-Klerx, H.J. Fusarium infection and trichothecenes in barley and its comparison with wheat. World Mycotoxin J. 2018, 11, 33-46. [CrossRef]

8. Šiukšta, R.; Vaitkūnienė, V.; Kaselytè, G.; Okockytè, V.; Žukauskaitė, J.; Žvingila, D.; Rančelis, V. Inherited phenotype instability of inflorescence and floral organ development in homeotic barley double mutants and its specific modification by auxin inhibitors and 2,4-D. Ann. Bot. 2015, 115, 651-663. [CrossRef] [PubMed]

9. Šiukšta, R.; Vaitkūnienè, V.; Rančelis, V. Is auxin involved in the induction of genetic instability in barley homeotic double mutants? Planta 2018, 247, 483-498. [CrossRef] [PubMed]

10. Ludwig-Müller, J. Bacteria and fungi controlling plant growth by manipulating auxin: Balance between development and defense. J. Plant Physiol. 2015, 172, 4-12. [CrossRef] [PubMed]

11. Murphy, B.R.; Doohan, F.M.; Hodkinson, T.R. Persistent fungal root endophytes isolated from a wild barley species suppress seed-borne infections in a barley cultivar. Biocontrol 2015, 60, 281-292. [CrossRef]

12. Qiang, X.; Ding, J.; Lin, W.; Li, Q.; Xu, C.; Zheng, Q.; Li, Y. Alleviation of the detrimental effect of water deficit on wheat (Triticum aestivum L.) growth by an indole acetic acid-producing endophytic fungus. Plant Soil 2019, 439, 373-391. [CrossRef]

13. Kazan, K.; Lyons, R. Intervention of phytohormone pathways by pathogen effectors. Plant Cell 2014, 26, 2285-2309. [CrossRef] [PubMed]

14. Chanclud, E.; Morel, J.B. Plant hormones: A fungal point of view. Mol. Plant Pathol. 2016, 17, 1289-1297. [CrossRef]

15. Robert-Seilaniantz, A.; Navarro, L.; Bari, R.; Jones, J.D. Pathological hormone imbalances. Curr. Opin. Plant Biol. 2007, 10, 372-379. [CrossRef] [PubMed]

16. Zhang, J.; Peng, Y.; Guo, Z. Constitutive expression of pathogen-inducible OsWRKY31 enhances disease resistance and affects root growth and auxin response in transgenic rice plants. Cell Res. 2008, 18, 508-521. [CrossRef] [PubMed]

17. Kidd, B.N.; Kadoo, N.Y.; Dombrecht, B.; Tekeoglu, M.; Gardiner, D.M.; Thatcher, L.F.; Aitken, E.A.; Schenk, P.M.; Manners, J.M.; Kazan, K. Auxin signaling and transport promote susceptibility to the root-infecting fungal pathogen Fusarium oxysporum in Arabidopsis. Mol. Plant Microbe Interact. 2011, 24, 733-748. [CrossRef] [PubMed]

18. Scheitz, K.; Lüthen, H.; Schenck, D. Rapid auxin-induced root growth inhibition requires the TIR and AFB auxin receptors. Planta 2013, 238, 1171-1176. [CrossRef] [PubMed]

19. Vaitkūnienė, V.; Čèsnienè, T.; Balčiūnienè, L.; Barysas, D.; Vaišnienè, V.; Rančelis, V. Immunodeficiency of barley allelic mutants tweaky spike. 4. Action of thiolic compounds and ascorbic acid on the frequency of mouldy grains. Biologija 1997, 2, 6-11.

20. Vaitkūnienè, V.; Balčiūnienè, L.; Varnaitè, A.; Rančelis, V. Response of barley immunodeficient mutants tweaky spike to salicylic acid in field conditions. Biologija 2005, 2, 13-20.

21. Vaitkūnienè, V.; Balčiūnienè, L.; Varnaitè, A.; Rančelis, V. Quality of seed material of barley tw type mutants according to susceptibility to micromycetes after treatment of previous generation with salicylic acid. Biologija 2005, 3, 41-45.

22. Vaitkūnienè, V.; Varnaitè, A.; Balčiūnienè, L.; Rančelis, V.; Mačkinaitė, R.; Leistrumaitè, A. Two types of revertants from the same homeotic barley mutants tweaky spike. Biologija 2006, 2, 18-23.

23. Vaitkūnienè, V.; Varnaitè, A.; Rančelis, V. Interaction of barley tweaky spike and laxatum mutations in F1 hybrids. Biologija 2004, 4, 10-15.

24. Mathur, S.B.; Kongsdal, O. Common Laboratory Seed Health Testing Methods for Detecting Fungi; Danish Government Institute of Seed Pathology for Developing Countries: Copenhagen, Denmark, 2003.

25. Mačkinaitè, R. Internal mycobiota of wild and cultivated common caraway (Carum carvi L.) seeds. Zemdirbyste 2011, 98, 183-194.

26. Aggarwal, R.; Gupta, S.; Banerjee, S.; Singh, V.B. Development of a SCAR marker for detection of Bipolaris sorokiniana causing spot blotch of wheat. Can J. Microbiol. 2011, 57, 934-942. [CrossRef] [PubMed]

27. Te Beest, D.E.; Paveley, N.D.; Shaw, M.W.; van den Bosch, F. Disease-weather relationships for powdery mildew and yellow rust on winter wheat. Phytopathology 2008, 98, 609-617. [CrossRef] [PubMed]

28. Junk, J.; Kouadio, L.; Delfosse, P.; El Jarroudi, M. Effects of regional climate change on brown rust disease in winter wheat. Clim. Chang. 2016, 135, 439-451. [CrossRef] 
29. Różewicz, M.; Wyzińska, M.; Grabiński, J. The most important fungal diseases of cereals—Problems and possible solutions. Agronomy 2021, 11, 714. [CrossRef]

30. Balčiūnienè, L.; Bieliūnienè, A.; Kazlauskaitè, D.; Vaitkūnienè, V.; Rančelis, V. Barley mutants with phenotypical gradient of spike development. Proc. Latv. Acad. Sci. B Nat. Exact Appl. Sci. 2001, 55, 207-211.

31. Sauer, D.B.; Burroughs, R. Disinfection of seed surfaces with sodium hypochlorite. Phytopathology 1986, 76, 745-749. [CrossRef]

32. Miché, L.; Balandreau, J. Effects of rice seed surface sterilization with hypochlorite on inoculated Burkholderia vietnamiensis. Appl. Environ. Microbiol. 2001, 67, 3046-3052. [CrossRef] [PubMed]

33. Davoudpour, Y.; Schmidt, M.; Calabrese, F.; Richnow, H.H.; Musat, N. High resolution microscopy to evaluate the efficiency of surface sterilization of Zea mays seeds. PLoS ONE 2020, 15, e0242247. [CrossRef]

34. Stotz, H.U.; Jikumaru, Y.; Shimada, Y.; Sasaki, E.; Stingl, N.; Mueller, M.J.; Kamiya, Y. Jasmonate-dependent and COI1-independent defense responses against Sclerotinia sclerotiorum in Arabidopsis thaliana: Auxin is part of COI1-independent defense signaling. Plant Cell Physiol. 2011, 52, 1941-1956. [CrossRef] [PubMed]

35. Llorente, F.; Muskett, P.; Sánchez-Vallet, A.; López, G.; Ramos, B.; Sánchez-Rodríguez, C.; Jordá, L.; Parker, J.; Molina, A. Repression of the auxin response pathway increases Arabidopsis susceptibility to necrotrophic fungi. Mol. Plant 2008, 1, 496-509. [CrossRef] [PubMed]

36. Meents, A.K.; Furch, A.; Almeida-Trapp, M.; Özyürek, S.; Scholz, S.S.; Kirbis, A.; Lenser, T.; Theißen, G.; Grabe, V.; Hansson, B.; et al. Beneficial and pathogenic Arabidopsis root-interacting fungi differently affect auxin levels and responsive genes during early infection. Front. Microbiol. 2019, 10, 380. [CrossRef] [PubMed]

37. Huang, S.; Zhang, X.; Fernando, W. Directing Trophic Divergence in Plant-Pathogen Interactions: Antagonistic Phytohormones with NO Doubt? Front. Plant Sci. 2020, 11, 600063. [CrossRef] [PubMed]

38. Petti, C.; Reiber, K.; Ali, S.S.; Berney, M.; Doohan, F.M. Auxin as a player in the biocontrol of Fusarium head blight disease of barley and its potential as a disease control agent. BMC Plant Biol. 2012, 12, 224. [CrossRef] [PubMed]

39. Luo, K.; Rocheleau, H.; Qi, P.F.; Zheng, Y.L.; Zhao, H.Y.; Ouellet, T. Indole-3-acetic acid in Fusarium graminearum: Identification of biosynthetic pathways and characterization of physiological effects. Fungal Biol. 2016, 120, 1135-1145. [CrossRef] [PubMed]

40. Kumar, J.; Schäfer, P.; Hückelhoven, R.; Langen, G.; Baltruschat, H.; Stein, E.; Nagarajan, S.; Kogel, K.H. Bipolaris sorokiniana, a cereal pathogen of global concern: Cytological and molecular approaches towards better control. Mol. Plant Pathol. 2002, 3, 185-195. [CrossRef]

41. Trail, F. For blighted waves of grain: Fusarium graminearum in the postgenomics era. Plant.Physiol. 2009, 149, 103-110. [CrossRef] [PubMed]

42. Wang, D.; Pajerowska-Mukhtar, K.; Culler, A.H.; Dong, X. Salicylic acid inhibits pathogen growth in plants through repression of the auxin signaling pathway. Curr. Biol. 2007, 17, 1784-1790. [CrossRef] [PubMed]

43. Navarro, L. A plant miRNA contributes to antibacterial resistance by repressing auxin signaling. Science 2006, 312, 436-439. [CrossRef] [PubMed]

44. Thomma, B.P.; Eggermont, K.; Penninckx, I.A.; Mauch-Mani, B.; Vogelsang, R.; Cammue, B.P. Separate jasmonate-dependent and salicylate-dependent defense response pathways in Arabidopsis are essential for resistance to distinct microbial pathogens. Proc. Natl. Acad. Sci. USA 1998, 95, 15107-15111. [CrossRef] [PubMed]

45. Bari, R.; Jones, J.D.G. Role of plant hormones in plant defence responses. Plant Mol. Biol. 2009, 69, 473-488. [CrossRef] [PubMed]

46. Guzman, J.D. Natural cinnamic acids, synthetic derivatives and hybrids with antimicrobial activity. Molecules 2014, 19, 19292-19349. [CrossRef]

47. Zhou, K.; Chen, D.; Li, B.; Zhang, B.; Miao, F.; Zhou, L. Bioactivity and structure-activity relationship of cinnamic acid esters and their derivatives as potential antifungal agents for plant protection. PLoS ONE 2017, 12, e0176189. [CrossRef]

48. Steenackers, W.J.; Klíma, P.; Quareshy, M.; Cesarino, I.; Kumpf, R.P.; Corneillie, S.; Araújo, P.; Viaene, T.; Goeminne, G.; Nowack, M.K.; et al. Cis-cinnamic acid is a novel, natural auxin efflux inhibitor that promotes lateral root formation. Plant Physiol. 2016, 173, 552-565. [CrossRef]

49. Sooväli, P.; Koppel, M.; Kangor, T. Effectiveness of seed treatment against Fusarium spp. and Cochliobolus sativus of spring barley in different conditions. Agron. Res. 2018, 15, 280-287.

50. Liatukas, Ž.; Supronienè, S.; Ruzgas, V.; Leistrumaite, A. Effects of organic seed treatment methods on spring barley seed quality, crop, productivity and disease incidence. Zemdirbyste 2019, 106, 241-248. [CrossRef]

51. Gupta, P.K.; Chand, R.; Vasistha, N.K.; Pandey, S.P.; Kumar, U.; Mishra, V.K.; Joshi, A.K. Spot blotch disease of wheat: The current status of research on genetics and breeding. Plant. Pathol. 2018, 67, 508-531. [CrossRef]

52. Lindsey, B.E.; Rivero, L.; Calhoun, C.S.; Grotewold, E.; Brkljacic, J. Standardized method for high-throughput sterilization of Arabidopsis seeds. J. Vis. Exp. 2017, 128, 56587. [CrossRef] [PubMed]

53. Nalewaja, J.D.; Woznica, Z.; Matysiak, R. 2,4-D amine antagonism by salts. Weed Technol. 1991, 5, 873-880. [CrossRef]

54. Nalewaja, J.D.; Matysiak, R. 2,4-D and salt combinations affect glyphosate phytotoxicity. Weed Technol. 1992, 6, 322-327. [CrossRef] 